\title{
Management of slipped capital femoral epiphysis: results of a survey of the members of the European Paediatric Orthopaedic Society
}

\author{
R. J. A. Sonnega $\cdot$ J. A. van der Sluijs • \\ A. M. Wainwright $\cdot$ A. Roposch $\cdot$ F. Hefti
}

Received: 31 May 2011/Accepted: 19 October 2011/Published online: 4 November 2011

(C) The Author(s) 2011. This article is published with open access at Springerlink.com

\begin{abstract}
Aim To determine current practice recommendations for the treatment of slipped capital femoral epiphysis (SCFE) among members of the European Paediatric Orthopaedic Society (EPOS).

Materials and methods A questionnaire with 4 case vignettes of a 12-year-old boy presenting with a stable and unstable SCFE. Each, stable and unstable slips, was of mild $\left(20^{\circ}\right.$ epiphyseal-shaft angle) and of severe $\left(60^{\circ}\right.$ epiphysealshaft angle) degree was sent to all members of EPOS in 2009 in order to ascertain their views on the best management of SCFE. Specifically, respondents were asked about the role of reduction, methods of fixation, prophylactic fixation of the non-affected hip, postoperative management and their view on the anticipated need for secondary surgery.

Results The response rate was $25 \%$ (72/287). The participating surgeons' average workload was $76 \%$ in paediatric orthopaedics, with mean 16 years of experience. Surgeons were most consistent in their advice for stable
\end{abstract}

R. J. A. Sonnega $(\bowtie) \cdot$ J. A. van der Sluijs Department of Orthopaedic Surgery, VU Medical Center, Boelelaan, 1007 MB Amsterdam, The Netherlands e-mail: rjasonnega@ hotmail.com

A. M. Wainwright

Nuffield Orthopaedic Centre, Windmill Road,

Oxford OX3 7LD, UK

\author{
A. Roposch \\ Great Ormond Street Hospital for Children, Institute of Child \\ Health, University College London, London, UK \\ F. Hefti \\ Department of Paediatric Orthopaedic Surgery, University \\ Children's Hospital Basel (UKBB), Basel, Switzerland
}

slips, where around $90 \%$ of the respondents did not recommend a reduction of the slip regardless of severity of slip. Seventy per cent of the respondents recommended the use of only one screw for fixation of a stable slip and for mild unstable slips. For severe unstable slips, $46 \%$ of surgeons recommended reduction only by positioning of the hip on the fracture table, $35 \%$ by manipulation and $11 \%$ advised open reduction. Responders were less consistent in their advice on the anticipated need for secondary osteotomies (in mild slips about $40 \%$ and about $60 \%$ in severe slips would advise an osteotomy) and on treatment of the contralateral hip (with $32 \%$ of surgeons recommending prophylactic fixation of the contralateral hip).

Conclusion Within members of EPOS, there is controversy on several aspects of the management of SCFE particularly on aspects of the treatment of unstable SCFE. Significance Members of EPOS predominantly use traditional means of treatment for patients with SCFE. In contrast, the more modern treatment concepts, such as open reduction via surgical dislocation, are rarely used.

Keywords Slipped · Capital · Femoral - Epiphysis ·

European · Paediatric · Orthopaedic · Survey ·

Questionnaire $\cdot$ Stable $\cdot$ Unstable $\cdot$ Treatment

\section{Introduction}

Slipped capital femoral epiphysis (SCFE) is a rare adolescent hip disorder affecting between 0.2 and 10 per 100.000[1]. The classification of SCFE as either stable (can walk with or without support), or unstable (cannot walk) [2], is useful to help determine prognosis and treatment. The current standard treatment is in situ central single-screw fixation or pinning without reduction. Most importantly, the 
traditional treatment of SCFE did not include any reduction of the slip [3].

Older techniques of open reduction such as Dunn's technique [4] have not gained popularity. There are controversial areas in the management of SCFE, particularly in the treatment of unstable slips. One area of disagreement is the reduction of the slip. The concern in the unstable type is the increased risk of avascular necrosis. Reduction of the less common unstable SCFE is feasible although the risk of avascular necrosis in this type is higher [5]. Recent studies show good results of open reduction $[6,7]$.

Another area of discussion is the method of fixation of the unstable SCFE. Whilst most surgeons use a single screw, biomechanical studies suggested that the use of 2 screws is superior. However, the use of 2 screws may increase the risk of inadvertent perforation of the proximal femoral epiphysis, which in turn could cause chondrolysis [8].

Also debated is the indication and type of corrective osteotomy in stable and unstable SCFE, both as primary or secondary interventions [3]. Contractures of the hip caused by severe deformation can be treated successfully by osteotomies, but it is unclear if these are best performed immediately or later.

Another area of debate is the indication for contralateral fixation: proponents argue for liberal contralateral fixation because of the high incidence of contralateral slip [9] and opponents argue for selective fixation because of the theoretical potential of complications [10]. Other areas are the duration of bed rest and protective weight bearing after fixation.

The aim of this study was to determine the opinions of paediatric orthopaedic surgeons about the best management of patients who present with untreated SCFE. We wanted to assess to what extent available scientific knowledge is applied and how they deal with the controversies. Specifically, we wanted to determine to what degree surgeons apply open reduction with surgical dislocation in the treatment of stable and unstable SCFE to assess the spread of this technique.

It is also acknowledged that several aspects of SCFE treatment were not addressed such as the timing of treatment, the use of capsular decompression and hardware removal. These were not addressed because they seem to have less influence on the outcome or their effect on outcome is according to the literature unclear.

\section{Materials and methods}

A questionnaire was sent to all members of the EPOS by e-mail in 2009 by the EPOS office. Completed questionnaires were returned by e-mail. Non-respondents were sent a reminder e-mail with replacement questionnaire on 2 occasions. Surgeons were asked to provide information about their professional background such as type of practice (teaching/non-teaching), years of experience in paediatric orthopaedics, percentage paediatric workload and country of practice.

The questionnaire included 4 case vignettes of a 12-year-old boy presenting with a stable and unstable [2] SCFE. Each, stable and unstable slips, was of mild $\left(20^{\circ}\right.$ epiphyseal-shaft angle) and of severe $\left(60^{\circ}\right.$ epiphyseal-shaft angle) degree [8]. X-rays are shown in Fig. 1a-h. The description of the 4 case vignettes included the slip angle in degrees with 2 radiographs for each case in antero-posterior and frog-lateral planes. The questionnaire explored the need for slip reduction, the best method of fixation, the anticipated need for secondary surgery, the need for prophylactic fixation of the contralateral unaffected hip and the nature of postoperative treatment. The response options were categorical and identical for each case using multiple choices with free-text comment options for each case vignette.

There were identical multiple choice questions for the management method that each respondent would use for each case

Analysis

Responses were collected and entered initially into an Excel spreadsheet (Microsoft, Redmond, Washington, USA). The data were subsequently transferred to a SPSS file for statistical analysis (SPSS Inc. version 12.0, Chicago, Illinois, USA). Answers are given in absolutes and percentages, with 95\% confidence intervals where appropriate.

\section{Results}

Of 357 members of EPOS, the e-mail addresses of 10 members were unknown and 60 were non-functioning, and 287 members were surveyed. Members were living in 45 different countries of which 10 having only one EPOS member. Response rate was $25 \%$ (72/287) with respondents of 24 countries. Among respondents, the mean duration of consultant practice was 16 years. Overall, $67 \%$ (48/72) of these surgeons spend more than $75 \%$ of their time in paediatric practice, and $74 \%$ were practising in teaching hospitals. Results of the multiple choice questions for the management method are summarised in Table 1.

Highest agreement was found on stable slips, where around $90 \%$ of respondents would not perform a reduction (85\%; 95\%CI 76-93\%). Most variation was found in reduction rate of severe unstable slips ( $46 \%$ by positioning $(95 \% \mathrm{CI} 35-57 \%), 35 \%$ by manipulation $(95 \% \mathrm{CI}$ 
Fig. 1 a Case 1 radiograph antero-posterior, $\mathbf{b}$ case 1 radiograph frog-lateral, c case 2 radiograph antero-posterior, d case 2 radiograph frog-lateral, e case 3 radiograph anteroposterior, $\mathbf{f}$ case 3 radiograph frog-lateral, $\mathbf{g}$ case 4 radiograph antero-posterior, $\mathbf{h}$ case 4 radiograph lateral
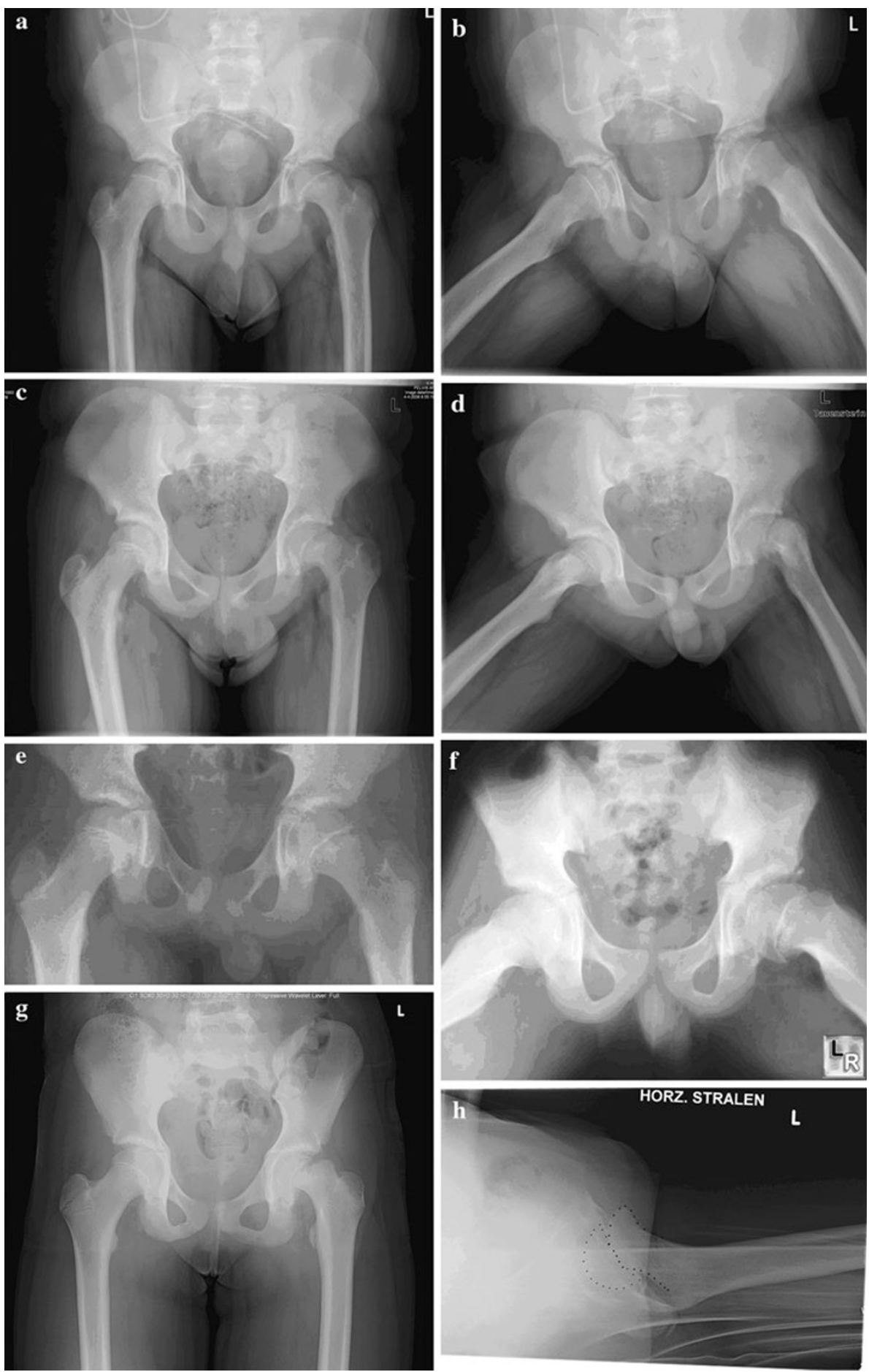

24-46\%) - no significant difference-and $11 \%$ by open reduction (95\% CI 4-18\%)).

Around $70 \%$ would use only one-screw fixation for all stable slips and mild unstable slips (67\%; 95\%CI 56-78\%).

There was no consensus on the suspected need of secondary osteotomies and prophylactic fixation.

Postoperatively most would recommend some days of bed rest followed by partial or none weight bearing.

\section{Discussion}

As stated, questionnaire studies on the treatment of unstable SCFE have already been published [11, 12]. This study is the first to assess the methods for both stable and unstable SCFE that surgeons across Europe would use at this time. We found that the in situ, one-screw fixation is currently the dominant technique. However, there is 
Table 1 Questionnaire results $(N=72)$

\begin{tabular}{|c|c|c|c|c|c|}
\hline Regarding & Options & $\begin{array}{l}\text { Stable } \\
\text { mild }\end{array}$ & $\begin{array}{l}\text { Stable } \\
\text { severe }\end{array}$ & $\begin{array}{l}\text { Unstable } \\
\text { mild }\end{array}$ & $\begin{array}{l}\text { Unstable } \\
\text { severe }\end{array}$ \\
\hline \multirow[t]{4}{*}{ Slip reduction } & None & $52(72 \%)$ & $52(72 \%)$ & $35(49 \%)$ & $6(8 \%)$ \\
\hline & Positioning on the fracture table & $15(21 \%)$ & $9(13 \%)$ & $25(35 \%)$ & $33(46 \%)$ \\
\hline & $\begin{array}{l}\text { Traction/manipulation (i.e. using force beyond } \\
\text { that necessary for positioning }\end{array}$ & $5(7 \%)$ & $6(8 \%)$ & $10(14 \%)$ & $25(35 \%)$ \\
\hline & Open reduction & $0(0 \%)$ & $5(7 \%)$ & $2(3 \%)$ & $8(11 \%)$ \\
\hline \multirow[t]{8}{*}{ Method of fixation } & Fixation by spica cast & $0(0 \%)$ & $0(0 \%)$ & $0(0 \%)$ & $0(0 \%)$ \\
\hline & Fixation using 1 screw & $56(78 \%)$ & $48(67 \%)$ & $48(67 \%)$ & $32(44 \%)$ \\
\hline & Fixation using 2 screws or more & $6(8 \%)$ & $7(10 \%)$ & $16(22 \%)$ & $26(36 \%)$ \\
\hline & Fixation using 1 or more $\mathrm{K}$ wires/pins & $4(6 \%)$ & $4(6 \%)$ & $4(6 \%)$ & $4(6 \%)$ \\
\hline & Alternative pinning (e.g Hansson pins) & $3(4 \%)$ & $2(3 \%)$ & $3(4 \%)$ & $2(3 \%)$ \\
\hline & Bone-graft epiphysiodesis & $0(0 \%)$ & $0(0 \%)$ & $0(0 \%)$ & $0(0 \%)$ \\
\hline & $\begin{array}{l}\text { In situ pinning with immediate trochanteric } \\
\text { osteotomy (e.g Imhauser, Southwick) }\end{array}$ & $2(3 \%)$ & $7(10 \%)$ & $1(1 \%)$ & $0(0 \%)$ \\
\hline & Subcapital wedge osteotomy and fixation & $1(1 \%)$ & $4(6 \%)$ & $0(0 \%)$ & $8(11 \%)$ \\
\hline \multirow[t]{4}{*}{ Secondary deformity correction } & None & $40(56 \%)$ & $27(38 \%)$ & $41(57 \%)$ & $31(43 \%)$ \\
\hline & Trochanteric osteotomy & $24(33 \%)$ & $35(49 \%)$ & $21(29 \%)$ & $32(44 \%)$ \\
\hline & Subcapital wedge osteotomy & $2(3 \%)$ & $7(10 \%)$ & $2(3 \%)$ & $3(4 \%)$ \\
\hline & Trimming femoral neck or bump resection & $6(8 \%)$ & $3(4 \%)$ & $8(11 \%)$ & $6(8 \%)$ \\
\hline \multirow[t]{2}{*}{ Contralateral fixation of unaffected hip } & Yes & $25(35 \%)$ & $21(29 \%)$ & $26(36 \%)$ & $21(29 \%)$ \\
\hline & No & $47(65 \%)$ & $51(71 \%)$ & $46(64 \%)$ & $51(71 \%)$ \\
\hline \multirow[t]{3}{*}{ Postoperative treatment } & Bed rest (overall mean in days after surgery) & $48(67 \%)$ & $54(75 \%)$ & $52(72 \%)$ & $54(75 \%)$ \\
\hline & No bed rest & $24(33 \%)$ & $18(25 \%)$ & $20(28 \%)$ & $18(25 \%)$ \\
\hline & Bed rest (mean days) & 5.9 & 8.0 & 6.6 & 9.0 \\
\hline \multirow[t]{4}{*}{ Mobilisation (weight bearing) } & Immediate full weight bearing in weeks & $12(17 \%)$ & $11(15 \%)$ & $4(6 \%)$ & $0(0 \%)$ \\
\hline & Reduced weight bearing in weeks & $35(49 \%)$ & $35(49 \%)$ & $30(42 \%)$ & $30(42 \%)$ \\
\hline & None weight bearing in weeks & $25(35 \%)$ & $26(36 \%)$ & $38(53 \%)$ & $42(58 \%)$ \\
\hline & $\begin{array}{l}\text { Average time to full weight bearing in weeks } \\
\text { (for reduced/none weight bearing groups) }\end{array}$ & 5.6 & 6.3 & 6.3 & 6.9 \\
\hline
\end{tabular}

variability in several aspects of SCFE treatment: e.g. the use of reduction and the limited spread of more aggressive techniques as the open reduction and osteoplasty.

This study has several limitations. The most important one was the low response rate: $25 \%$ that parallels the rate from the POSNA study (33\%) [12] but is lower than the Dutch or British Paediatric Orthopaedic Society survey $(65 \%)$ [11]. The e-mail character of the survey including e-mail reminders cannot be the only factor for this disappointing rate since this method was also used by the Dutch or British Paediatric Orthopaedic Society study. The questionnaire was distributed through the EPOS contact office 'Symporg' and spread by e-mail to the e-mail address given by the members themselves. The e-mails were sent with the following heading 'EPOS questionnaire on SUFE' by 'Symporg'. Two reminding e-mails were sent. Explaining factors responsible for the low response rate could be the following: recipients possibly associated 'Symporg' with administrative and not clinical matters. Another factor could be that some pharmaceutical firms use questionnaires partially as promotional activity and members could have considered 'Symporg's' e-mail to be in this light. Furthermore, a few EPOS members work in the same orthopaedic institute and possibly considered 2 identical answers as redundant. To maximise the response rate we could have, contacted the people before sending the questionnaire, make them more personal and preferably kept them shorter according to Edwards [13].

Although the response rate is low, the questionnaire with respondents with an average paediatric orthopaedic workload of $75 \%$ spread over 24 countries gives some indication about the types of techniques used and their variability.

Another fundamental limitation of this, as any other survey is, that the difference between stated and actual behaviour is unknown. 
In stable SCFE, little variability in treatment was expected in treatment given the generally good results of in situ fixation [3]. As expected the number of closed reductions in stable SCFE was minimal for mild slips. Closed reduction would be attempted by a minority $28 \%$ (including careful positioning), and few would use more than 1 screw (8-10\% for mild stable slips and severe stable slips).

The variability in treatment of unstable SCFE is larger. In general, the advice from the literature suggests that reduction should only be performed by positioning. We found up to $35 \%$ of the study group would attempt closed reduction by manipulation. This contrast with a metaanalysis [5] that advices no or cautious reduction.

In spite of biomechanical and clinical data suggesting the adequacy of single-screw fixation in unstable SCFE $[14,15]$, a substantial number of surgeons (up to $36 \%$ ) would use two-screw fixation for additional stability in spite of an increased risk of complications. 'A substantial part of the responders would use treatments (reduction by manipulation and two-screw fixation) not supported by the literature. A recent study [16] suggests that a substantial proportion of the responders use methods based on personal conviction instead of scientific data'.

\section{Variability in indications for secondary reconstructions}

A large retrospective follow-up study showed disappointing results after femoral neck osteotomies for severe, mostly stable slips with AVN occurring in 33\% [17]. It is important to point out that this high rate of AVN occurred in reduction techniques that did not employ a surgical dislocation approach. AVN rates in the latter should be smaller. The cited study advised restrained indications and osteotomies at lower (trochanteric or base of neck) levels. In accordance with this, and other studies, most osteotomies advised are intertrochanteric, predominantly performed secondarily (40-50\% vs. $10 \%$ primarily). It was not expected that a substantial number of osteotomies $(32 \%)$ were recommended in the mild (20 degree of slip) SCFE. As these mild slips may not lead to functional contractures, the indication is probably improvement in the long term. However, on this aspect, most studies report negative results compared to natural history [3].

We have difficulty explaining this high percentage in mild slips. Either there is some misunderstanding or the benign natural history of the mild slips is less known.

In general, we have difficulty explaining other items showing variability, not supported by the literature. A recent EPOS questionnaire on the treatment of Perthes disease showed a similar finding. In that study major interventions were advised in children with an almost predictable benign natural history. That study concluded that indications for the treatment of LCPD are based more on the personal experience of the surgeon rather than on scientific data [16]. The value of the present SCFE questionnaire is that is quantifies this fact and could be used to stimulate state of the art lectures aimed at improving the spread of available knowledge.

Variability in indication for contralateral fixation

Given the lack of data on advantage/disadvantage, the practice in case of this hypothetical 12-year-old patient was about $32 \%$ was in favour of contralateral fixation. Stability and severity having little influence (mild $35 \%$ and severe $29 \%$ ). This seems higher than of that reported by the POSNA survey (12\%) [12] and the Dutch or British Paediatric Orthopaedic Society surgeons (9\%) [11]. Possibly the Hansson study [18] from Sweden with its high incidence of contralateral slips influenced EPOS members more than POSNA members.

Variability in management of postoperative treatment

In stable SCFE $16 \%$ of the responders used full weight bearing, but only $6 \%$ in mild unstable SCFE and none in severe unstable SCFE. This is probably related to the absence of evidence regarding the optimal period of reduced weight bearing. 'However, based on experimental data [15] reduced weight bearing in stable SUFE is not indicated and is even debatable in unstable slips. As such a more patient friendly after treatment may be justified'.

Easier techniques spread faster than more complex ones [18]. This is illustrated by the predominance of the in situ pinning technique 30 years since the original publication of in situ pinning in 1977. This technique has replaced more historical classic techniques. The use of casts and epiphysiodesis seems extinct. The spread of more complex techniques is slower: among the participants of this survey, the technically more demanding method of surgical dislocation and open reduction of the slipped epiphysis according to Ganz introduced in 2001 [19] have until now only a few users. Besides technical aspects, it is possible that uncertainty about long-term prognosis and the AVN rate in the hand of less experienced surgeons are other factors delaying the spread of this technique.

\section{Conclusion}

Within the EPOS, there is variation on many aspects of the management of SCFE. The one-screw in situ pinning is, 30 years after its introduction, the dominant technique having replaced older techniques. New methods for reduction and fixation are less widely practiced, and open reduction is performed in $5-10 \%$ of the severe SCFE. 
Comparing the current practice with state of the literature, areas of improvement in care are more consensus on the restricted indications for reconstructions in mild slips as evidence for improvement in the natural history is absent. Possibly, the development of guidelines could be useful.

Another point is the safety of immediate weight bearing in stable SCFE. The majority prefer weeks of none to partial weight bearing. However, about $17 \%$ of the responders allow full weight bearing for mild stable SCFE and apparently without anecdotal problems leading to more restricted after treatment. Possibly, there is room for more patient friendly improvement in this aspect.

This questionnaire indicates areas where knowledge is lacking on the optimal treatment of SCFE, and we highlight areas where multi-centre studies could be focussed to identify the most effective method of management.

Acknowledgments The authors would like to thank the responders for their answering this EPOS questionnaire and the EPOS organisation for their help in distributing the questionnaire.

Open Access This article is distributed under the terms of the Creative Commons Attribution Noncommercial License which permits any noncommercial use, distribution, and reproduction in any medium, provided the original author(s) and source are credited.

\section{References}

1. Loder RT, Aronsson DD, Dobbs MB, Weinstein SL (2001) Slipped capital femoral epiphysis. Instr Course Lect 50:555-570

2. Loder RT, Richards BS, Shapiro PS, Reznick LR, Aronson DD (1993) Acute slipped capital femoral epiphysis: the importance of physeal stability. J Bone Joint Surg Am 75(8):1134-1140

3. Loder RT, Aronsson DD, Weinstein SL, Breur GJ, Ganz R, Leunig M (2008) Slipped capital femoral epiphysis. Instr Course Lect 57:473-498

4. Dunn DM (1964) The treatment of adolescent slipping of the upper femoral epiphysis. J Bone Joint Surg Br 46:621-629

5. Lowndes S, Khanna A, Emery D, Sim J, Maffulli N (2009) Management of unstable slipped upper femoral epiphysis: a metaanalysis. Br Med Bull 90:133-146

6. Leunig M, Slongo T, Kleinschmidt M, Ganz R (2007) Subcapital correction osteotomy in slipped capital femoral epiphysis by means of surgical hip dislocation. Oper Orthop Traumatol 19(4):389-410
7. Ziebarth K, Zilkens C, Spencer S, Leunig M, Ganz R, Kim YJ (2009) Capital realignment for moderate and severe SCFE using a modified Dunn procedure. Clin Orthop Relat Res 467(3): 704-716

8. Southwick WO (1967) Osteotomy through the lesser trochanter for slipped capital femoral epiphysis. J Bone Joint Surg Am 49(5):807-835

9. Hagglund G (1996) The contralateral hip in slipped capital femoral epiphysis. J Pediatr Orthop B 5(3):158-161

10. Kocher MS, Bishop JA, Hresko MT, Millis MB, Kim YJ, Kasser JR (2004) Prophylactic pinning of the contralateral hip after unilateral slipped capital femoral epiphysis. J Bone Joint Surg Am 86-A(12):2658-2665

11. Witbreuk M, Besselaar P, Eastwood D (2007) Current practice in the management of acute/unstable slipped capital femoral epiphyses in the United Kingdom and the Netherlands: results of a survey of the membership of the British Society of Children's Orthopaedic Surgery and the Werkgroep Kinder Orthopaedie. J Pediatr Orthop B 16(2):79-83

12. Mooney JF III, Sanders JO, Browne RH, Anderson DJ, Jofe M, Feldman D et al (2005) Management of unstable/acute slipped capital femoral epiphysis: results of a survey of the POSNA membership. J Pediatr Orthop 25(2):162-166

13. Edwards PJ, Roberts I, Clarke MJ, Diguiseppi C, Wentz R, Kwan I et al (2009) Methods to increase response to postal and electronic questionnaires. Cochrane Database Syst Rev 8(3):MR 000008

14. Karol LA, Doane RM, Cornicelli SF, Zak PA, Haut RC, Manoli A (1992) Single versus double screw fixation for treatment of slipped capital femoral epiphysis: a biomechanical analysis. J Pediatr Orthop 12(6):741-745

15. Kibiloski LJ, Doane RM, Karol LA, Haut RC, Loder RT (1994) Biomechanical analysis of single- versus double-screw fixation in slipped capital femoral epiphysis at physiological load levels. J Pediatr Orthop 14(5):627-630

16. Hefti F, Clarke NM (2007) The management of Legg-CalvePerthes' disease: is there a consensus?: A study of clinical practice preferred by the members of the European Paediatric Orthopaedic Society. J Child Orthop 1(1):19-25

17. Hagglund G, Hansson LI, Ordeberg G, Sandstrom S (1986) Slipped capital femoral epiphysis in southern Sweden. Long-term results after femoral neck osteotomy. Clin Orthop Relat Res 210:152-159

18. Hansson LI, Hagglund G, Ordeberg G (1987) Slipped capital femoral epiphysis in southern Sweden 1910-1982. Acta Orthop Scand Suppl 226:1-67

19. Ganz R, Gill TJ, Gautier E, Ganz K, Krugel N, Berlemann U (2001) Surgical dislocation of the adult hip a technique with full access to the femoral head and acetabulum without the risk of avascular necrosis. J Bone Joint Surg Br 83(8):1119-1124 